\title{
The Promotion of Liquid Phase Sintering of Boron-Containing Powder Metallurgy Steels by Adding Nickel
}

\author{
Ming-Wei Wu ${ }^{a}$ and Wen-Zhang Cai ${ }^{b}$ \\ Department of Materials and Mineral Resources Engineering, National Taipei University of Technology, Taipei 10608, Taiwan, ROC
}

\begin{abstract}
Boron is a feasible alloying element for liquid phase sintering (LPS) of powder metallurgy (PM) steels. This study investigated the effect of nickel (Ni), which is widely used in PM steels, on the liquid phase sintering of boron-containing PM steels. The results showed that the addition of $1.8 \mathrm{wt} \% \mathrm{Ni}$ does not apparently modify the LPS mechanism of boron-containing PM steels. However, adding $1.8 \mathrm{wt} \% \mathrm{Ni}$ slightly improves the LPS densification from $0.60 \mathrm{~g} / \mathrm{cm} 3$ to $0.65 \mathrm{~g} / \mathrm{cm} 3$, though the green density is reduced. Thermodynamic simulation demonstrated that the presence of Ni lowers the temperature region of liquid formation, resulting in enhanced LPS densification. Moreover, original graphite powders remains in the steels sintered at $120{ }^{\circ} \mathrm{C}$. These graphite powders mostly dissolve into the base iron powder when the sintering temperature is increased from $1200^{\circ} \mathrm{C}$ to $1250^{\circ} \mathrm{C}$.
\end{abstract}

\section{Introduction}

LPS is an effective sintering method for decreasing the porosity of PM steels. Adding boron to PM steels induces a eutectic reaction and facilitates the densification. Thus, boron-containing PM steels, including alloy steels, stainless steels, and other steels, have been extensively studied [1-7]. Moreover, the effects of various alloying elements, such as carbon, molybdenum, and chromium, on LPS of boroncontaining PM steels have also been investigated.

Xiu et al. [2] studied the effect of carbon on LPS of Fe-Mo-B-C steel and found that increasing the carbon content from $0.2 \mathrm{wt} \%$ to $0.44 \mathrm{wt} \%$ improves the densification. $\mathrm{Wu}[7]$ recently investigated the influences of carbon and molybdenum on the LPS of Fe-0.4B steel and found that the addition of $0.5 \mathrm{wt} \% \mathrm{C}$ can increase the liquid volume by $5.4 \mathrm{vol} \%$ at $1250{ }^{\circ} \mathrm{C}$ and thus improve the sintered density. Also, adding $1.5 \mathrm{wt} \% \mathrm{Mo}$ to $\mathrm{Fe}-$ $0.4 \mathrm{~B}-0.5 \mathrm{C}$ steel can further increase the liquid volume by 1.4 vol\% at $1250{ }^{\circ} \mathrm{C}$ and thus the densification. Lozada and Castro [5] studied the effect of chromium content on boron-containing PM stainless steels and reported that increasing the chromium content from $11.8 \mathrm{wt} \%$ to 30 wt $\%$ inhibits LPS.

$\mathrm{Ni}$ is also an important alloying element in PM steel due to its versatility [8-11]. The addition of $\mathrm{Ni}$ can increase both the mechanical strength and the toughness [9-11]. However, the role of Ni on the LPS of PM steels has rarely been studied. The objective of this study was to investigate the effect of Ni on the LPS densification and microstructure of boron-containing PM steel.

\footnotetext{
${ }^{\mathrm{a}}$ Corresponding author: $\underline{\text { mwu@ntut.edu.tw }}$
}

\section{Experimental procedure}

To identify the influence of Ni on the LPS of boroncontaining PM alloy steels, the commercially available Fe-0.5Mo (ATOMET 4001, QMP) and Fe-1.8Ni-0.5Mo (ATOMET 4601, QMP) prealloyed powders were used as the base powders to prepare the $\mathrm{Fe}-0.5 \mathrm{Mo}-0.4 \mathrm{~B}-0.5 \mathrm{C}$ and Fe-1.8Ni-0.5Mo-0.4B-0.5C steels in this study. The designations of $\mathrm{Fe}-0.5 \mathrm{Mo}-0.4 \mathrm{~B}-0.5 \mathrm{C}$ and $\mathrm{Fe}-1.8 \mathrm{Ni}-$ $0.5 \mathrm{Mo}-0.4 \mathrm{~B}-0.5 \mathrm{C}$ were $\mathrm{FMBC}$ and $\mathrm{FMBC}-1.8 \mathrm{Ni}$, respectively. The two base powders were blended with $0.4 \mathrm{wt} \%$ elemental boron powder and $0.6 \mathrm{wt} \%$ graphite powder in a mixer for 60 minutes to produce the FMBC and $\mathrm{FMBC}-1.8 \mathrm{Ni}$ powder mixtures. The combined carbon content of FMBC and FMBC-1.8Ni was about 0.5 $\mathrm{wt} \%$ due to decarburization during high temperature sintering. Moreover, $0.75 \mathrm{wt} \%$ of lubricant (ethylene bisstearamide) was also added into the two powder mixtures.

The previous two powder mixtures were uniaxially compacted at a pressure of $600 \mathrm{MPa}$ to prepare green compact disks with a diameter of $13 \mathrm{~mm}$ and a thickness of $7 \mathrm{~mm}$. The green densities of FMBC and FMBC-1.8Ni were 6.94 and $6.84 \mathrm{~g} / \mathrm{cm} 3$, respectively, due to differences in powder compressibility. The green compacts were heated at $5{ }^{\circ} \mathrm{C} / \mathrm{min}$ to $550{ }^{\circ} \mathrm{C}$ and then held for 15 minutes to remove the lubricant. The specimens were then heated at $10{ }^{\circ} \mathrm{C} / \mathrm{min}$ to sintering temperatures $\left(1150{ }^{\circ} \mathrm{C}, 1200{ }^{\circ} \mathrm{C}\right.$, and $\left.1250{ }^{\circ} \mathrm{C}\right)$ without holding, followed by furnace cooling. An argon atmosphere was used for both the debinding and the sintering.

The sintered densities of the two steels were tested using the Archimedes' method. The specimens were 
sampled, ground, polished, and then etched with a solution of $2 \%$ Nital and $4 \%$ Picral. An optical microscope $(\mathrm{OM})$ and a scanning electron microscope (SEM) were used to observe the microstructure. To estimate the role of Ni on LPS, a quasi-binary phase diagram was calculated using Thermo-Calc software (Thermo-Calc Software, Stockholm, Sweden) coupled with a TCFE7 database.

\section{Results and discussion}

Fig. 1 and 2 show the OM microstructures of FMBC and FMBC-1.8Ni steels sintered at various sintering temperatures, respectively. Those images show that the addition of $1.8 \mathrm{Ni}$ in the FMBC steels did not obviously affect the densification and microstructure. Few carbides can be observed in the microstructures sintered at 1150 ${ }^{\circ} \mathrm{C}$ and $1200{ }^{\circ} \mathrm{C}$, indicating that the carbon was not dissolved into the iron matrix during $1200{ }^{\circ} \mathrm{C}$ sintering. Furthermore, in Fig. 1(c), rings of ferrite are quite apparent between the continuous boride and pearlite. This phenomenon can be attributed to the diffusion of carbon atoms from the periphery of the iron powder for participation in the liquid formation [7]. The addition of $1.8 \mathrm{Ni}$ affected the local distributions of alloying elements and thus eliminated the ferritic rings between the continuous boride and pearlite.

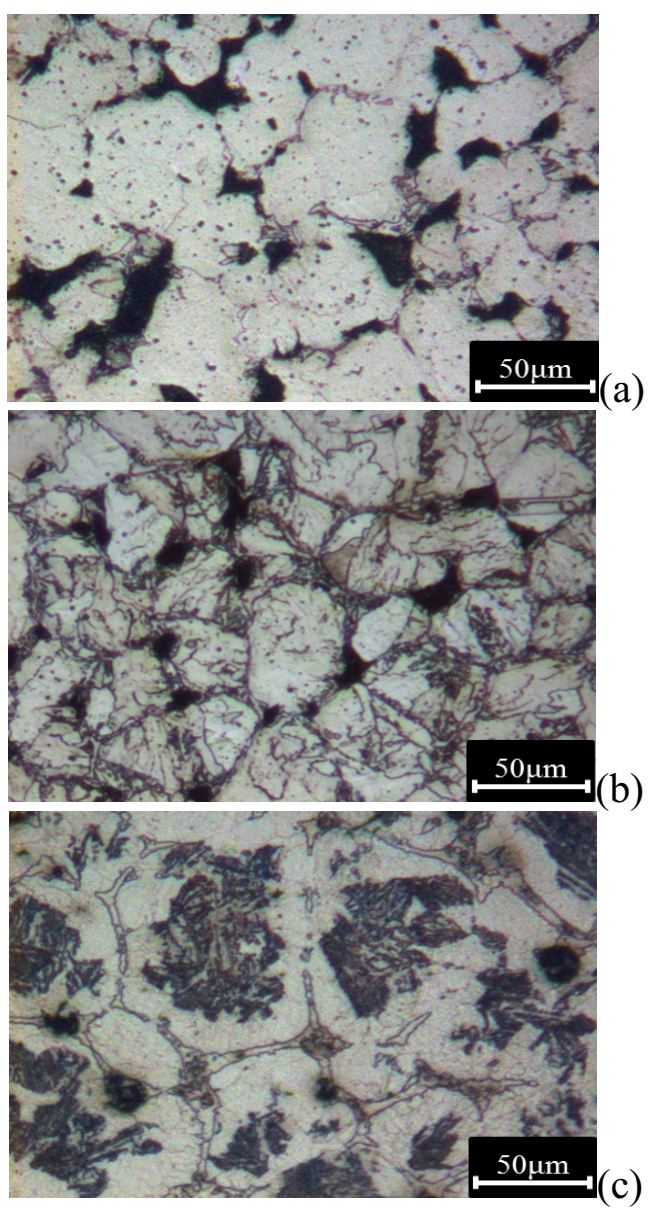

Figure 1. The $\mathrm{OM}$ microstructures of $\mathrm{FMBC}$ steels sintered at (a) $1150^{\circ} \mathrm{C}$, (b) $1200^{\circ} \mathrm{C}$, and (c) $1250^{\circ} \mathrm{C}$.
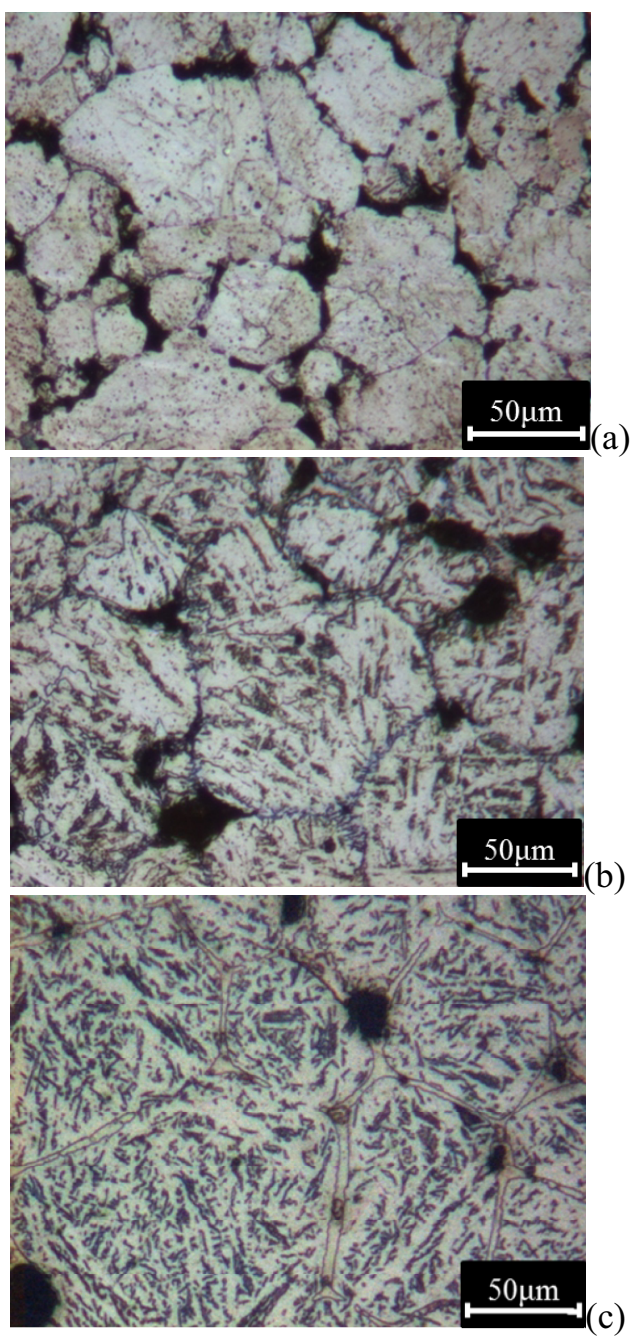

Figure 2. The $\mathrm{OM}$ microstructures of $\mathrm{FMBC}-1.8 \mathrm{Ni}$ steels sintered at (a) $1150^{\circ} \mathrm{C}$, (b) $1200^{\circ} \mathrm{C}$, and (c) $1250^{\circ} \mathrm{C}$.

Fig. 3 shows the SEM microstructures of FMBC$1.8 \mathrm{Ni}$ steel sintered at $1200{ }^{\circ} \mathrm{C}$. Unexpectedly, many black particles were still embedded in the pores. These black particles consisted of up to $90 \mathrm{wt} \% \mathrm{C}$, according to EPMA quantitative analysis, indicating that these particles were the original graphite powders. These analyses clearly show the presence of graphite even after sintering at $1200{ }^{\circ} \mathrm{C}$. However, most of the graphite particles disappeared after $1250{ }^{\circ} \mathrm{C}$ sintering. The microstructure of the original iron powder was changed from ferrite to pearlite or bainite when the sintering temperatures were increased from $1200{ }^{\circ} \mathrm{C}$ to $1250{ }^{\circ} \mathrm{C}$, as shown in Figs. 1 and 2. 


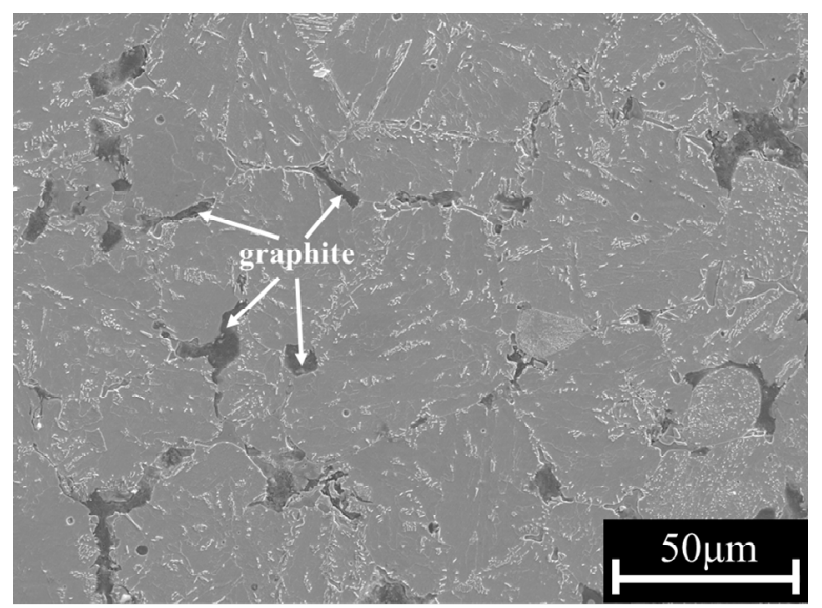

Figure 3. The presence of graphite in the FMBC-1.8Ni steels sintered at $1200^{\circ} \mathrm{C}$.

The green densities and sintered densities of the two steels as a function of sintering temperature are plotted in Fig. 4. The sintered density of FMBC steel sintered at $1250{ }^{\circ} \mathrm{C}$ was $0.04 \mathrm{~g} / \mathrm{cm} 3$ greater than that of FMBC-1.8Ni. However, the differences in the sintered density at 1250 ${ }^{\circ} \mathrm{C}$ and the green density of FMBC and FMBC-1.8Ni steels were $0.60 \mathrm{~g} / \mathrm{cm} 3$ to $0.65 \mathrm{~g} / \mathrm{cm} 3$, respectively. These results demonstrate that at $1250{ }^{\circ} \mathrm{C}$, the $1.8 \mathrm{Ni}$ addition improved the sintered density slightly, by $0.05 \mathrm{~g} / \mathrm{cm} 3$.

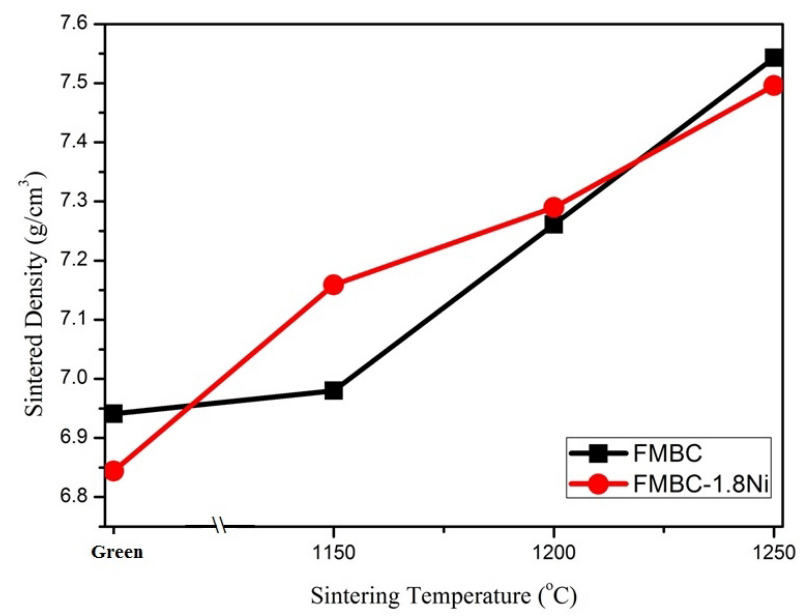

Figure 4. The green densities and sintered densities of the two steels as a function of sintering temperature.

To further understand the role of $\mathrm{Ni}$, a quasi-binary phase diagram of FMBC-xNi steel was calculated using the Thermo-Calc software, as demonstrated in Fig. 5. In Fig. 5, the symbols FCC, L, and M2B represented austenite, liquid, and boride, respectively. The simulation shows that the equilibrium phases of FMBC steel at 1250 ${ }^{\circ} \mathrm{C}$ were $\mathrm{L}+\mathrm{FCC}$, indicating that liquid could be generated in an equilibrium state. Moreover, increasing the $\mathrm{Ni}$ content slightly decreased the temperature of liquid formation and shifted the L+FCC area to a lower temperature. Thus, the $1.8 \mathrm{Ni}$ addition could slightly increase the liquid volume during LPS and improved the sintered density after $1250{ }^{\circ} \mathrm{C}$ sintering. The results obtained by thermodynamic calculation corresponded well to those of sintered density, as shown in Figs. 4 and 5. In the future, the influence of $\mathrm{Ni}$ concentration in the
LPS of boron-containing PM steels will be further clarified.

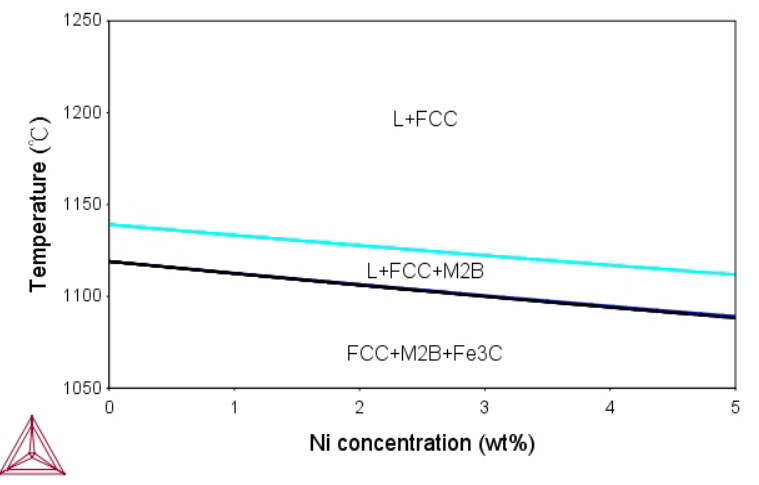

Figure 5. The simulated quasi-binary phase diagram of FMBC$\mathrm{xNi}$ steels.

\section{Summary}

Adding $1.8 \mathrm{Ni}$ to FMBC steel can slightly increase the sintered density from $0.60 \mathrm{~g} / \mathrm{cm} 3$ to $0.65 \mathrm{~g} / \mathrm{cm} 3$, though the green density is impaired.

The thermodynamic simulation shows that increasing the Ni content can slightly decrease the temperature for liquid formation and shift the L+FCC area to a lower temperature, resulting in improved LPS densification.

Many graphite powders still exist even after sintering at $1200{ }^{\circ} \mathrm{C}$. When the sintering temperature is increased from $1200{ }^{\circ} \mathrm{C}$ to $1250{ }^{\circ} \mathrm{C}$, carbon atoms in the graphite powders diffuse into the base iron powder, and the graphite powders mostly disappear.

\section{Acknowledgement}

The authors thank the Ministry of Science and Technology of the Republic of China for funding under contract number MOST 103-2221-E-027-132.

\section{References}

1. R. M. German, K. S. Hwang, and D. S. Madan, Powder Metall. Int. 19, 15(1987)

2. Z. Xiu, A. Salwen, X. Qin, F. He, and X. Sun, Powder Metall. 46, 171(2003)

3. M. Sarasola, T. G. Acebo, and F. Castro, Acta Mater. 52, 4615(2004)

4. H.Ö. Gulsoy, Scripta Mater. 52, 187(2005)

5. L. Lozada and F. Castro, Adv. Powder Metall. Part. Mater. 78 (2011)

6. M. Momeni, C. Gierl, H. Danninger, and A. Avakemian, Powder Metall. 55, 54(2012)

7. M.W. Wu, Metall. Mater. Trans. A 46, 467(2015)

8. M. Nabeel, R. Frykholm, and P. Hedström, Powder Metall. 57, 111(2014)

9. M.W. Wu, K.S. Hwang, and H.S. Huang, Metall. Mater. Trans. A 38, 1598(2007)

10. F. Bernier, P. Plamondon, J.P. Baïlon, and G. L'Espèrance, Powder Metall. 54, 559(2011)

11. M.W. Wu, G.J. Shu, S.Y. Chang, and B.H. Lin, Metall. Mater. Trans. A 45, 3866(2014) 